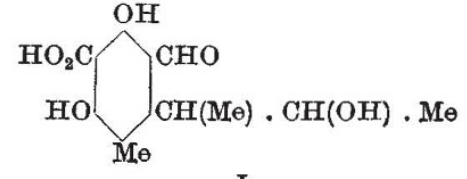

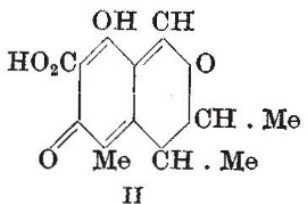

I

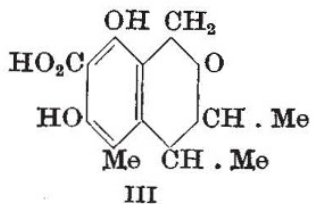

form of $(\mathrm{I})$, most satisfactorily explains $(a)$ the ready aromatization of the compound in warm acid or alkaline media with the extrusion of formyl (as formic acid) and carboxyl (as carbon dioxide) groups; (b) the formation of formic acid and not formaldehyde or glyoxylic acid on the ozonolysis of citrinin and its ester ; and (c) the formation of a stable dihydro derivative (III) with simultaneous aromatization. The structure (III) ascribed to the latter compound is in agreement with its blue ferric reaction, which is characteristic of $\gamma$-resorcylic acids. On the basis of formula (II), the phytochemical formation of citrinin may conceivably proceed by way of the intermediate (I).

It would seem that the claim by $\mathrm{Cram}^{1}$, that the isolation of authentic 4-methyl-5-ethylresorcinol from citrinin completely eliminates the formula proposed for the latter by Robinson et $a l .^{3}$, can scarcely be sustained at present. The above formula retains the original suggestion of a hemi-quinone type of kernel.

J. P. BROWN

N. J. CARTwRIGHT

A. RoBertson

W. B. WHALLEY

Department of Organic Chemistry, University, Liverpool.

${ }^{1}$ Cram, J. Amer. Chem. Soc., 70, 440 (1948).

${ }^{2}$ Compare Brown, M.Sc. Thesis, May 1947, University of Liverpool.

'Robinson et al., Phil. Trans. Roy. Soc., B, 220, 297 (1931).

\section{Nitration of Simple Heterocycles}

IN a recent letter in Nature ${ }^{1}$, Schofield and Swain comment, inter alia, upon the failure of resonance theory to explain non-nitration of isoquinoline in position 7 : the following results may be of interest.

In the course of work in these laboratories we have been led to investigate the nitration products of 3:4-dihydroisoquinoline derivatives and have found, for example, that 1-p-nitrophenyl-3: 4-dihydroisoquinoline gives an 80 per cent yield of the 7-nitro derivative, this structure being proved by comparison with the product of cyclization of $N$ - $p$ nitrobenzoyl-2-(4'-nitrophenyl)ethylamine. On the other hand, 1-p-nitrophenylisoquinoline yields 85 per cent of 1-p-nitrophenyl-5-nitroisoquinoline, identified by conversion to 1-p-chlorphenyl-5-chlor-isoquinoline and comparison with a synthetic sample. Such sub. stitution in the isoquinoline ring may be compared with that of quinoline which is nitrated in the 5 and 8 positions, whereas tetrahydroquinoline has been shown to nitrate in position $7^{2}$, a result compatible with expectation since $o$-toluidine yields 4-nitro-2aminotoluene ${ }^{3}$. Similarly, isoquinoline is nitrated principally in the 5 position with a small proportion of the 8-isomer. Nitration of reduced isoquinoline has escaped attention, and investigation of the products of nitration of $3: 4$-dihydro- and $1: 2: 3: 4$-tetrahydroisoquinoline is now being undertaken, when we expect to isolate the 7-nitro derivatives in accordance with the above result and by comparison with the nitration of $o$-cyantoluene, which yields 4-nitro-2cyantoluene $^{5}$, and of 2-phenylethylamine, which has been shown to give 45 per cent of the para and 18 per cent of the meta isomer ${ }^{6}$. Results will be reported in detail elsewhere.

We wish to thank the directors of May and Baker, Ltd., for permission to publish these results.

David W. Mathieson

A. MCCoubrey

Research Laboratories,

May and Baker, Ltd.,

Dagenham, Essex. May 5.

${ }^{1}$ Nature, 161, 690 (1948).

2 Hoffmann and Königs, Ber., 16, 736 (1883). v. Braun, Grabowski and Rawicz, Ber., 46, 3173 (1913).

${ }^{3}$ Noelting and Collin, Ber., 17, 265, 268 (1884).

'Andersag, Chem. Zentr., 1, 3595 (1934).

${ }^{5}$ Landsberger, Ber., 31, 2880 (1898).

' Ehrlich and Pistschimuka, Ber., 45, 2431 (1912).

\section{Production of Quinolyl and Pyridyl Anions during Decarboxylation}

IT has been shown ${ }^{1,2}$ that when picolinic and quinaldinic acids are decarboxylated in the presence of aldehydes and ketones, $\alpha$-pyridyl and $\alpha$-quinolyl carbinols of the type $\mathrm{Py}(\mathrm{Qy}) \cdot \mathrm{CH}(\mathrm{OH}) \cdot R$ are produced in good yields (40-80 per cent). The course of this reaction has been formulated in terms of the intermediate formation of $\alpha$-pyridyl and $\alpha$-quinolyl anions, which are formally of cyanide ion type ${ }^{1,2}$. The possibility that the cyanide function might by con. jugation be extended to the $\gamma$-position has been confirmed recently by Mislow $^{3}$, who has obtained $\gamma$-pyridyl diphenylcarbinol by the decarboxylation of isonicotinic acid in benzophenone. We now report that we have prepared $\gamma$-quinolyl diphenylcarbinol, m.p. $247^{\circ}$, from cinchoninic acid and benzophenone in yields of 7-10 per cent; we are developing the reaction as a possible route to quinine analogues.

We also find that, in the presence of decarboxylating quinaldinic and picolinic acids, it is possible to exchange the alkoxy groups of esters for pyridyl and quinolyl groups and to effect substitution by these groups at cationoid (electrophilic) centres in aromatic molecules; we take this to confirm our view that quinolyl and pyridyl anions are produced during the decarboxylation process.

Dyson Perrins Laboratory,

B. R. BRown

D. LL. HAMMick

University, Oxford. April 15.

${ }^{1}$ Dyson and Hammick, J. Chem. Soc., 1724 (1937).

${ }^{2}$ Ashworth, Daffern and Hammick, J. Chem. Soc., 809 (1939),

${ }^{3}$ J. Amer. Chem. Soc., 69, 2559 (1947).

\section{Ecology of Sponges}

THe statement has often been made that sponges can be found growing almost up to high-tide mark. As a result of close observation over miles of shore in a dozen different localities on the south and west coasts of Britain during the past twelve months, I have no hesitation in saying that only exceptionally are sponges found above mid-tide level. Even then, the most to be seen are a few undersized specimens of Hymeniacidon perlevis ( $=H$. sanguinea Auctt.) in 